\title{
Focietp Droceedings
}

\author{
JOINT MEETING \\ OF THE \\ NEW YORK NEUROLOGICAL SOCIETY
}

AND THE

PHILADELPHIA NEUROLOGICAL SOCIETY.

Held in Philadelphia, Nov. 24, 1906.

The President of the Philadelphia Neurological Society, DR. D. J. MCCARTHY, in the Chair.

(Continued from page 419.)

\section{DISCUSSION ON APHASIA, ESPECIALLY WITH REFERENCE TO THE VIEWS OF MARIE.}

Dr. Charles K. Mills said that neurologists owe some gratitude to Pierre Marie for reviving intercst in the study of aphasia and for showing that some of the classical views about cerebral disorders of speech are worthy of re-examination, if not of revision. Marie has already found some supportcrs for his view, and has awakened the attention or opposition of distinguished neurologists like Dejerine and von Monakow.

The task assigned to Dr. Mills was simply that of opening a discussion which it is hoped will bring out new data and a full expression of opinion from the members of our two societies. After a glance at the views of Marie and the manner in which these have been opposed by Dejerine, he would content himself with a rather dogmatic presentation of personal views.

The most important of Marie's assertions are: that auditory, visual and motor speech centers do not exist; that aphasic phenomena are not due to interference with auditory, visual, or other images, but to intellectual deficit, this deficit causing difficulty in the comprehension of speech and interfering with numcrous didactic processes; and that Broca's convolution takes no part in the function of speech and its lesions in the production of aphasia. Considering how universal has been the opposite of this last opinion about Broca's convolution, this is perhaps the most startling of his assertions. Marie admits that Wernicke's aphasia, Broca's aphasia, and anarthria are clinical facts, but explains these facts, especially as regards Broca's aphasia, very differently from his predecessors, - asserting that Broca's aphasia is nothing but Wernicke's aphasia complicated with anarthria, or anarthria complicated with Wernicke's aphasia. Anarthria, as he understands the term, is due to lesion of the lenticula and its environment. According to Marie, the regions, lesions of which produce aphasia, are all included in Wernicke's zone, which he defines as composed of the supramarginal (inferior parietal) and inframarginal gyres and the posterior extremities of the first two temporal convolutions, -in other words that cortical region composed of the gyral masses which curve around the extremities of the Sylvian and the parallel fissures. 
In his replies to Marie, Dejerine maintains the classical or at least the usually accepted views regarding aphasia, holding with reference to sensory aphasia that the long aecepted theory of centers for sensorial images cannot be successfully attacked, and that the diminution of intellis gence sometimes exhibited by aphasies is dependent upon disruption or disturbance of the cerebral meehanism of speech rather than the aphasia upon the intellectual loss or deficit. He stoutly maintains that Broca's convolution plays an important part as a speech centre, explaining the cases in which it is involved and aphasia does not result by the compensatory action of the opposite hemisphere, and cases of Broca's aphasia without lesion of Broea's convolution by the fact that the motor speech zone includes other parts, as the anterior insula and the foot of the seeond frontal gyre. He adheres to his theory of sub-cortical motor aphasia due to lesion of the fibers entering and leaving Broea's convolution. He holds that the existenec of the real or the apparent sensory aphasia in motor aphasies is usually only temporary, and in any case is not to be explained in the way that Maric suggests. Anarthria or dysarthria, according to Dejerine, is due to lesion of the motor projection fibcrs and is different from cortical or subcortical motor apliasia. He contends also that the cases with numerous or extensive lesions described by Marie are cases of total aphasia, the lesions involving all or a large part of the speech zone ; also that Maric fails to recognize cases in which Wcrnicke's zone and the lenticula are not involved and yet the Broca syndrome is present. Dejerine believes that a purcly unilateral lesion of the lenticula does not produce anarthria.

Dr. Mills' views regarding the questions in dispute between Marie and Dejcrine are largcly those of the latter, differing in some particulars which will appear in the course of the discussion. He summarized these views as follows:

I. The centers eoncerned with speech may in a general way be designated as sensory and motor.

2. Under sensory should be included lowcr and higher sensory centers, the lower being places of storage for the auditory and visual memories of words, letters and all else which take part in language on its recipient side. The higher sensory areas have sometimes been tcrmed the concept areas; they are regions in whieh names bccome associated with the ideas of objects named, and in which probably other somewhat evolved and complex sensory processes takc place.

3. The lower and higher scnsory areas for speech and their associated structures are all included in the posterior association area of Flechsig, the eonerete coneept or eonerete nemory field of the writer. They do not belong to the cerebral primordial or projection fields, but have been evolved out of these,-a fact important to remember when considering the question of intellectual defieit in aphasics.

4. For the purposes of this discussion all the sensory centers for speech,--auditory and visual,- - may be regarded as included in Wernicke's zone as dcfined by Marie, with the addition of some portion of the third temporal convolution. It needs only to be remembered when speaking of the supramarginal convolution as a part of Wernicke's zone that only the caudal or posterior half of this convolution is to be taken into account.

5. The cortical motor center for speeeh is situated in the insula and in the hinder part of the left third frontal convolution. 
6. In the lower third of the precentral convolution are situated the cortical motor centers, concerned with phonation, articulation, and facial expression,-in short with all movements which take part in spoken language. These motor centers taken together constitute an utterance or executive speech center, and are of necessity connected with Broca's convolution.

7. The motor center for speech is not connected by projection fibers directly with the bulbar nuclei, but indirectly through the motor cortex. Whether the cortical specch centers proper are connected directly with the lenticula or other basal centers not bulbar, is not yet positively determined, but probably the cortical exccutive conter is connected with the lenticula and thalamus.

8. The lenticula has motor functions, and like the precentral cortex is subdivided into centers for movements of different parts of the body, as for the leg, arm, and face, necessarily therefore having within its borders motor centers of somc sort concerncd with articulate spcech. The part played by the lenticula in motor spccch, however, is different from that which is performed cither by the motor center included in the insula and Broca's convolution, or in the cortical center for movements of the face and tonguc.

With regard to the ccrcbral zonc of spccch, and also other regions of the brain, we are not much bcyond the thrcshold of our knowledge of the subdivision of function.

In some quarters a tendency to rebcl against the extreme differentiation of the brain into areas and subarcas and conters is exhibited, but close attention to the facts, particularly those which are being obtained through clinico-pathological observation, wonld sccm to show that this differentiation is even much greater than has been supposed by the most ardent believer in localization.

Sensory aphasia, according to Marie, is the only real aphasia. He would have us belicve that all our slowly and patiently acquired views with regard to memorial images, anditory, visual and for all the senses, so far at least as the discussion of aphasia and the cerebral phenomena of speech are concerned, should be cast aside; that in Wernicke's zone, as already dcfincd, are not the long rccognizcd auditory and visual centers and their claborate conncctions, but that this zone is an intellectual area or center and that the aphasia of Wcrnicke is due, not to disturbance of auditory and visual processes, lower and higher, variously combined, but to intellectual disintegration.

The centers, visual and anditory, concerned with speech are, as Dr. Mills has already stated, part of the great concrctc memory field, or posterior association arca of Flechsig. It must be admitted that this is a region concerned with thinking, with concrcte idcas, but these very forms of mental activity have for their hascs sensorial images and their correlation with each other and with other cercbral proccsses. The posterior association area is a psychic zone, higher in grade than the fields of projection and lower than the prefrontal psychic zone concerned with abstract conception and the highest intellectual functions. The intellectual deficit described by Marie and observed hy all students of aphasia, is conditioned by destruction and disturbance of the sensorial cerebral centers, and of the structures connecting these with othcr parts of the brain. When Marie admits, as he does, that Wernicke's aphasia is a clinical type with 
the characteristics described by Wernicke and others, he largely admits all that is asserted by those who hold to the more commonly accepted views regarding auditory and visual aphasias. One may, if he so choose, regard the two sets of convolutions which curve around the extremitiea of the Sylvian and of the parallel fissure, as an audito-visual "intellectual" center-a center composed of auditory and visual subcenters with cor relating intrinsic and extrinsic structures.

One might ask Marie in this connection some questions of such simplicity as to scarcely appear to have scientific value. What for example does he regard as the basis of the intellectual activity of his psychic center? Is he going back to the ancient mythical and metaphysical ideas of some spirit dwelling in this or that part of the brain? Is intelligence with him some indefinite essence separated into different parts, each dwelling in some particular region of the cerebrum? If he recognizes higher and lower grades of intelligence or intellectuality, does he regard them as dependent upon some subdivided entity which he calls the intellect, or does he believe that they are in some way correlatcd to sensation and motion and to physiological processes of perception and apperception which have their anatomical substrata in different regions of the brain? In brief, what is his exact definition of an intellectual center, disturbance or disintegration of which gives rise for instance to the intellectual deficieney which is present in his aphasia?

It scemed to Dr. Mills that Dejerine has the best of the argument as regards the question of intellectual deficit depending upon interference with sensorial processcs, and not these processes upon intellectual impairment. It must be said, however, that Dejerine, in common with others from which list Dr. Mills could not exclude himself, may have spoken at times without due consideration of aphasics having no impairment of intelligence, just as at other times too great stress may have been laid upon intellectual impairment. If the cases are closely studied, it is true, as Marie asserts, that such impairment of intelligence will be found in varying degree.

Too much cmphasis cannot be placed in this connection upon the individual capacitics, natural and acquired. $\Lambda$ phasic patients like those seen at the Bicêtre, the Salpêtrière, and at the Philadelphia General Hos. pital, are most frequently individuals of no grcat natural endowment and sometimes of little or no education. Lesions which interfere with the cerebral zone of speech either on its sensory or motor side will cause in such persons an impairment of ability to carry out mental processes to a greater degree than in those of a higher order of intelligence. Dr. Mills had again and again noted striking differences in the ability of aphasics to understand and carry out directions or to act for themselves along lines requiring intelligence, such patients presumably from their symptoms suffering from lesions of the brain of similar extent and location.

In discussing the part played by sensorial images, attention should be more strongly fixed upon the fact that it is not alone destruction or disturbance of sensory centers concerned with interior speech that causes aphasic phenomena and interference with intellectual processes, but that these sensory centers are of various grades of simplicity and complexity according as they administer to lower or higher sensory concepts, and also that the disruption or disturbance of the associations between sensory centers for the different senses, and for lower and higher conceptual pro- 
cesses are the agents in causing aphasia as much as the assaults which are made upon isolated sensorial centers. Moreover, the breaking of association between the audito-visual portion of the cerebral zone of speech with all its intricate associations and correlations and the motor portion of the speech zone and the projection system add both to the aphasia regarded simply as a speech disorder, and as due to deranged or diminished intelligence, but that the loss of interference with memorial images is the main cause of the aphasia, is fundamental.

The references of Dejerine to insanity are interesting in the support which they give to his views. He refers for instance to the fact that hallucinations among the insane support the idca of scnsorial images. He does not perhaps lay sufficient stress upon the fact that such hallucinations and illusions are more dependent upon the disruption of associations between centers than they are upon the interference or destruction of the centers thomselves. The writcr gave some attention to this subject in a paper recently presented to the section on psychology of the British Medical Association at the necting lreld in Toronto, September, 1906. As shown in that paper the study of the hallucinations of the insane is in a large and proper sense a study of an intercsting phase in cerebral localization, a view which has been supported in the past by many alienists and neurologists. Dejerinc's reference to general paretics is one which must appeal to every alienist. How often do we observe cases of general paresis with nore or lcss advanced demcntia still showing no true aphasia, either sensory or motor, notwitlsstanding the fact that because of the nature and site of some of the lcsions, anarthric or dysarthric affections of spcech may be present?

The symptomatology of discase of Wernicke's zone will differ according to the size and cxtension of the lesion. If the lcsion be, as it usually is, of considerable extcnt, the main symptoms will bc word deafness (sometimes nearly complcte, although more often partial), word dumbness more or less pronounced, dyslexia, paralexia or alcxia, slowness or difficulty in word speaking (paraphasia), repctition of the same words and phrases, and at times abnormally rapid paraphasic speech or logorrhea. The sensory aphasic, whatever niay be the limitations or the extent of the lesion producing his symptoms, if such lesion is confined to Wernicke's zone, is not deprived of the powcr of speech, like the motor aphasic suffering from a lesion of the cortex or subcortex, or cortex and subcortex of the insula and Broca's convolution.

Dr. Mills did not give much space to the consideration of the clinicopathological evidence favoring the existencc of centers for word seeing, word hearing and other forms of incmorial imagery, and also of tracts in the audito-visual zone connecting these centers with each other and with other parts of the brain. Such evidence is to be found in the wellknown works and articles on aphasia, and to a certain extent it has been marshalled by Dejerinc in his part of the interesting discussion now under way. Dr. Mills had from time to time recorded cases with such symptoms as word blindness, word deafness, word dumbness, object blindness, alexia, paralexia, paraphasia and the like; and believed that most of these will at least stand the test involved in referring them to lesions of a true auditovisual zone.

It needs to be said that word deafness and word blindness are rarely monosymptomatic, although Marie admits that the latter may be: and 
that cerebral lesions are only in very rare instances either purely cortical or purely subcortical.

Probably one of Dr. Mills' own cases, now well known in the literature of the subject, approached as nearly as any recorded case to an illustration of word deafness due to an isolated and limited lesion.

This case was first recorded by him in I8gr. The two cerebral hemispheres are still in his possession and have been brought here this evening. The patient, fifteen years before her death, had an apoplectic attack, previous to this time not having had any known affection of hearing, sight, or speech. As the result of this attack slie became word deaf, and had a marked form of paraphasia, although she continued to read, and to some extent to write. She was described, however, as having mixed up her words in writing. She could hear and appreciate musical and ordinary sounds, like a bell, a knock, or the tick of a clock. Six years before her death, she had a second apoplectic attack and soon after became totally deaf, or nearly so, as to sounds as well as to words. She was also, as a result of this second seizure, partially hemiplegic on the left side. At the necropsy in this case, even before the membrancs were removed, it was noticed that the first temporal convolution was smaller and thinner than usual, and that at the postcrior cxtrenity of this convolution about opposite the upward turn of the posterior extrcmity of the Sylvian fissure, was a depression which included also a part of the adjoining second temporal convolution, the depression being about seven-eighths of an inch in diameter. This depression. as was proved subsequently, was the result of an old embolic or hemorrhagic cyst. On the right side was an old and very extensive hemorrhagic cyst which had completely destroyed the first, and almost completely the second, temporal gyre, the island of Reil, the retroinsular gyrcs, the lower extrcmities of the central gyres, and to a large extent, but exactly how much was not determincd, the ganglia and capsules. The first temporal, retroinsular, and subfrontal (Broca's convolution) gyres wcre greatly wastcd.

We can have a motor aphasia which is distinct in its symptomatology from a sensory or sensorimotor aphasia or from a dysarthria or anarthria, the dysarthria and anarthria being used in the commonly accepted sense of impossibility or difficulty in articulating, enunciating and vocalizing words or expressions. Motor aplasia due to lesion of the cortex and its immediate subcortex may be complete or partial, according to the degree of destruction of the cortex and subcortex. In complete motor aphasia the patient is unable to speak at all, although as is well known, in cases almost complete he sometimes retains a single or a few recurring utterances. If the case is one of absolutely pure motor aphasia, the patient may have no paresis of the organs concerned with speech. He is unable to recall words which describe objects or which are used in the formation of phrases or sentences. Apparently he cannot arrange language for utterance. One of his difficulties might he expressed as Broadbent so long ago expressed it, as "inability to propositionize"; and indeed this fault or loss has been expressed in various ways, none of them entirely satisfactory. The patient is word dumb, but more than this. It is said that the psychomotor memories concerned with language are lost, but this does not make the matter nutch clearer. Again, it is sometimes said that the motor aphasic cannot build words, phrascs, or sentences. Not a few cases of motor aphasia as secn in practice are partial at first and become 
complete as in a case of advancing tumor. Sometimes the motor aphasia is complete or nearly so for a time, but disappears and reappears, these varying conditions of motor speech disturbance being due to variations in the condition of the lesion and in the physiological activities of the parts associated with the centers affected by it.

The motor aphasic may exhibit some dysarthria or anarthria, this being especially noticeable with regard to certain sounds as those made by dentals and labials. It may be a question whether the dysarthria or anarthria of a motor aphasic is due to the influence of the lesion on the true motor speech center, or on adjoining or connected parts, as the centers at the foot of the precentral convolution or perhaps those in the lenticula.

Motor aphasics may have trouble both in reading and in comprehending spoken words, but these defects are not the same in degree and probably not the same in kind as in the case of sensory aphasics. Troubles of this kind present early in a case of motor aphasia due to a severe lesion may disappear entirely and not be a part of the residual syndrome. They are doubtless due either to the effects produced by the edema and other temporary states or to the diaschysis of von Monakow-that is, to interference with the physiological actions of the parts with which the center attacked is anatonically and physiologically connected. Von Monakow, in expounding diaschysis diagrammatically, indicates a lesion placed in some portion of the cortex. Coming to and going from this place of lesion are association fibers to other portions of the cortex, and also commissural connection through the callosum to the other hemisphere, and presumably, from the other hemisphere through the callosum; also fibers going from the cortex to the bulbar nuclei, etc. A certain physiological interchange of function takes place between the different but correlated areas, so that destruction of one area necessarily causes a change in the physiological state of other centers or areas with which it is correlated.

Von Monakow calls attention to the importance of giving more heed to negative cases; also to the fact that much still remains to be learned with regard to many plases of the subject of aphasia, Marie for this reason deserving the thanks of neurologists for the interest which he has excited in the subject.*

The difficulty in understanding spoken language sometimes exhibited by motor aphasics is so little marked as to need considerable study for its detection. The amount of this difficulty is conditioned to a certain extent by the original intelligence. education and training of the aphasic.

In a correct sense the cercbral zone of speech is a single great mechanism, but it has nuany parts. If the machinery in one part is interfered with, the effects of such interference may extend to all parts.

One case recorded by Dr. Mlills has helped to convince him of the part played by Broca's convolution and the insula in the function of speech. This patient was long'an inmate of the insane department of the Philadelphia General Hospital. Dr. Nills saw him first about nine years after en apoplectic attack which left him aphasic. His language was very restricted. He could speak only a very few words or phrases, or one or two very short sentences. Word dumbness was a marked feature of the ease, although he learned by training to name objects like a watch, a pencil or

*This reference to von Monakow was introduced since the discussion at the meeting of the two societies, his paper having appeared about that time. 
knife, with some facility. The expressions he made use of were such as "very pretty," "thank you," etc. He had a curious recurring utterance which he made use of when he attempted to read aloud. It was, "England, oh, my soul, England, oh, my soul!" He would read, apparently understanding what he was reading, and then make use of this expression in a loud and rather oratorical tone. He was apparently able to read, although with difficulty. He was tested as regards this matter, for instance, by asking him to select words from different parts of the page which he was reading, and which he would do correctly, although taking some time. What he said was said with distinctness and clearness. No paralysis of the muscles of articulation, enunciation or phonation was present. He had no anarthria or dysarthria in the usual sense in which these words are employed, but was a true motor aphasic. He could understand what was said to him. The patient was able to recognize objects by touch, hearing, taste and smell, but as a rule was not able to name the object. The case was clearly one of marked, although not absolutely complete, motor aphasia. The paticnt could write many single words or short combinations of words correctly, holding his pen or pencil with ease and Grmness.

In some of the cases in which motor aphasia has been present, the convolution of Broca apparently remaining intact, lesions have been present in both the external capsule and the anterior part of the internal capsule, parts wlich are closely related to the insula and the convolution of Broca.

In the cases cited by Marie in which so-called motor aphasia was present, and in which the lenticular nucletts was implicated in a destructive lesion, parts neighboring on this ganglion were also nearly always involved. These parts included the insula and the external capsule. The insula and its subjacent cortex, by many as by the writer, have been included with Broca's convolution and its subcortex in the so-called motor center for specch; and the probabilities are that in the large lesions to which Marie refers the subcortex of at least part of the motor speech center is involved.

The fact that atrophy or involution of Broca's convolution sometimes takes place after destructive lesion involving Wernicke's zone on one or both sides is an argument in favor of the vicw that Broca's convolution is an integral part of the zone of speech. In the personal case of sensory ephasia to which Dr. Mills had referred, that of a patient who had suffered from word deafness and paraphasia bccause of a lesion limited to a small area at the junction of the hinder portions of the first and second temporal convolutions, and who afterwards became totally deaf from a destructive lesion attacking the temporal and central convolutions and other parts of the opposite side, the post-mortem examination showed that Broca's convolution among other parts was greatly atrophied. The attack, causing the word deafness, it will be remembered, occurred fifteen years before death, and that which brought about complete cerebral deafness, nine years before death.

While sensorial and motor aphasia are separate and independent clinical syndromes, many of the cases of aphasia observed in practice are, because of the nature and especially because of the extent of the lesions causing them, sensorimotor, or as they are sometimes called, mixed or total aphasias. The lesions in these cases often involve, as is well known, such 
parts as the superior temporal convolution, the insula, Broca's convolution and its subcortex, the central and the supramarginal convolutions, the lenticula and the external and internal capsules. They are instances of widespread destruction of all parts irrigated by the middle cerebral artery. In other instances the cercbral regions supplicd by this artery are involved in varying degree, giving a more or lcss confusing smyptomatologty made up of a combination of scnsory and motor spcech phenomena with other symptoms.

Marie's views would seem to be largely built up upon the record of cases of these so-called total aphasias.

What is necessary in this discussion is in the first place to marshal the symptomatology of cases in which the lesions have been confined to the audito-visual (Wernicke's) zone; secondly, that of cases with lesions limited to Broca's convolution or the insula and its immediate subcortex: and thirdly, that of cases in which the lesions were confined to the lenticula. Cases of each of these descriptions are on record and give a particu. lar symptomatology.

Much stress is laid by Dejerine upon the distinction between cortical and subcortical motor aphasia. Such a distinction can no doubt at times be made; at least isolated cases of subcortical motor aphasia have been recorded, their symptomatology differing somewhat from that of the cortical forms of .Broca's aphasia. For reasons, however, which must be rery clear to every practical neuropathologist the lesions causing the aphasia, in fact massive lcsions of all sorts, are very rarely purely cortical. The vessel which closes or which is broken has its branches both in gray and white matter, and hence the softened area or the hemorrhagic cyst usually involves both. It is probable, as Dejerine says, that a subcortical motor aphasia, if of pure type, will leave certain powers or capacities of the patient,-as that of writing,-intact, or but little affected, but such a case will be of rare occurrence. The usual symptom picture, whether the lesion be in Broca's convolution or the insula or in both, or in whatever part of the cerebral zone of speech, is one that is due to a lesion which is jointly cortical and subcortical. Dr. Mills excluded here those cases of lesion of the internal capsule and corona radiata, sometimes observed, in which no portion of the gray matter, either cortical or central, is diseased; but even in capsular lesions and in lesions of the corona outside of the usually accepted cerebral zone of speech the gray matter is often involved.

Motor aphasia, according to Marie, is simply Wernicke's aphasia plus anarthria. Dr. Mills did not see how this definition is to be accepted unless we give a new meaning to anarthria, which indccd Marie seems to have done. The generally accepted definition of anarthria is that it is a defect or difficulty in specch, especially connected with articulation. Even if wc expand this definition as Marie has sugcested, so as to include defects of the expiratory, phonatory and articulatory ncchanism, it is still clear that such an anarthria does not constitute motor aphasia in the accepted sense. Many of the motor aphasics whom Dr. Mills had studied have presented no anarthria or dysarthria. Some partial motor aphasics are dysarthrics; some monoplcgics or hemiplegics have anarthria or dysarthria which is regarded by careless observers as motor aphasia, but anarthria and motor aphasia are quite distinct, although the two may be combined in the same case. Add to the well recognized phenomena of sensory 
aphasia such as partial word deafness, paraphasia, etc., an anarthric defect of speech, and the resultant will not be a true motor aphasia. Defective vocalization and articulation will be added to the sensorial phenomena, and yet the paticnt may be able to speak, although in a stumbling manner.

To what is anarthria or dysarthria due when present from a cerebral lesion,-from a lesion above the hulb? In some cases it is undoubtedly due, as is now well known, to lesions usually bilateral of the internal capsule; in others to lesions of the subcortex of the facial and orolingual region, and in others to lesions of the orolingual cortex itself.

Dejerine believes that anarthria producing the pseudo-bulbar syndrome never occurs from a unilateral lesion, either cortical or capsular, the cases observed by him having always bccn instances of bilateral lesions. He belicves that the centers which come into play in the mechanism of speech have in reality a bilateral cortical representation.

The question of the correctness of Marie's views with regard to the part played by lesions of the lenticula in the production of motor aphasia necessarily involves the cliscussion of the entire question of the functions of this body. Dr. Mills had the opportunity of making personal observations on several cases with necropsies in which destructive disease of the lenticula was present. The lesions, however, were rarely strictly confined to the lenticula. In the laboratory of neuropathology of the University of Pennsylvania, Dr. William G. Spiller las the specimens from some of these cases, with others collected by himself. One or two of these specimens have been brought liere for the inspection of those taking part in this discussion. Later it is the intention of Dr. Spiller and the writer to take up the question of the functions of the lenticula largely from the point of view of personal clinicopathological studies.

Probably the work of Mingazzini on the symptomatology of lesions of the lenticular nucleus is the most valuable contribution to our knowledge of this stibject. As the result of carefully made personal observations and of a study of cases recorded by others he concludes that a focal lesion, even if of small size, which involves only the lenticular nucleus never fails to manifest itself with motor disturbances, these motor symptoms showing themselves as dissociated or generalized paralysis or paresis to which are sometimes added irritative symptoms.

Mingazzini discusses the speech disorders which he, in common with Nothnagel and others who precedcd him, believe result from destructive lesions of the lenticula. These are particularly described as dysarthrias, and Mingazzini holds that they would appear to result only from lesions of the left lenticula. He gives cases with nccropsies demonstrating the fact that lesions of the right lenticula do not, while those of the left if peculiarly situated do, cause dysarthric affections.

BIBLIOGRA PHY.

Marie, Pierre. Semaine Médicale, May 23, 1906.

Marie, Pierre. Scmaine Médicalc, Oct. I7, I906.

Dejerine, J. La Prcsse Médicale, July I I, I906.

Dejerine, J. La Presse Médicale, July i8, I906.

Mills, Charles K. Lniversity Mledical Magazine, November, I891; also Amcrican Journal of the Medical Sciences. Scptember, 1904.

Von Monakow. Neurologisches Centralblatt. No. 22, I906.

Mingazzini, Giovanni. Sulla sintomatologia delle lesioni del nucleo lenticolare, I902. 
Dr. James Hendrie Lloyd said that Marie's paper on aphasia is more important for what it indicates than for what it really says. As a pronouncement on the subject of aphasia it is noteworthy chiefly for attempting to tear down all the work that has been done by others, and to erect instead an edifice which is largely theoretical and purcly Marie's. Viewed in this light it does not scem to be deserving of all the attention it is receiving; and Dr. Lloyd failed to see that it marks an epoch.

But from the standpoint of what it indicates-as showing, for instance, a tendency-Marie's paper is of some significance. It is a protest, or a reaction against the extreme academic school which has long been paramount. This academic, or diagrammatic school has elaborated this subject of aphasia beyond all reason. A recent author gives twenty-eight varieties of aphasia. There is hardly a monograph in which this excessive subdivision is not more or less in evidence. We see the nicest analyses made, and the whole subject partitioned out, each variety being assigned to a limited area of the brain cortex. Dr. Lloyd did not hesitate to say that these fine-spun schemes are not so much in accord with bedside observation as they are mere evidences of a burning of the midnight oil. We even hear it said that there are special and distinct centers for the grammatical parts of speech, as nouns and names, but for his part Dr. Lloyd had never been able to subscribe to those extreme views, and he believed he was within bounds when he said that it is impossible at the bedside to verify all this theoretical psychology.

His own doubts on this subject have been growing greater and graver for some ycars. Bedside observations, very faithfully made and in large hospital clinics with ample material, have not enabled him to make many of the fine distinctions which are so popular. In most cases that he saw the phenomena are mixed. Thus with motor aphasia there is some auditory aphasia and word blindness, especially in bad cases, and in the early stages even of mild cases. There is also, as Marie points out, some failure of intelligence, or mental confusion, so that it is most difficult to say just how much is aphasia properly so-called, and how much is due to mental defect. He had been in the habit for some years at Blockley of calling these cases sensori-motor aphasia, as indicating that both the sensory and motor elements of speech are involved. He knew that the criticism is brought against these views that those who hold them are lacking in the power of precise observation. But that criticism is the worst kind of a begging of the question. Precise observation is not a monopoly, even of those who can discern twenty-eight varieties of aphasia.

In a recent casc at Blockley there was complete motor aphasia, with some degree of word deafness and word blindness; also very evident mental dullness; but the brain cortex on gross inspection, after hardening in formaline, was not involved, and the lesion was confined to the internal capsule and lenticular region. Dr. Lloyd has now two cases of right-sided hemiplegia under his care in the Methodist Episcopal Hospital in neither of which is there the slightest evidence of aphasia of any kind. He did not agree with Marie that the cortex must necessarily be involved in order that there should be aphasia proper, for he had certainly seen genuine aphasia in cases of purely lenticular lesions. He said this, however, with due appreciation of the fact that we have no right on mere naked eye inspection to say that the cortex is not involved when there are large underlying capsular lesions. Even a microscopic examination might not suffice to determine whether the brain cells in life had been able to 
functionate in cases in which the circulation had been so seriously obstructed as by large underlying hemorrhages or softenings.

This led him to say a word about the difficulty of interpreting pathological changes. We have in many of these cases great ripping lesions, tearing up large areas of the brain substance. Even in one or two of Marie's pictures it looks as though large parts of the side of the brain had been torn out. In such cases precise conclusions are often unwarranted. The damage even in small lesions is often much more extensive than it seems to the naked eye. He had seen a minute but fatal hemorrhage in the spinal cord which seemed to be confined to the anterior parts of the posterior columns, but under the microscope the damage was seen to be much more extensive, acting in fact like a total transverse lesion. So in the brain, a seemingly small lesion may be responsible for much greater and more widespread damage than it is creditcd with. Observation in some of these cases can hardly be exact; and as some of them are reported and described no proper attempt is made to delimit the lesion. We are totally deprived of all opportunity to experiment in order to prove anything in aphasia, for of course the anthropoid apes are of no value for such a purpose, and we cannot experiment on the human subject under ether. Dr. Lloyd often feels like protesting against the dogmatic statements that are based on improperly observed pathological changes. Will the time ever come when some enthusiast will have the temerity to excise carefully the so-called auditory speech center or the angular gyrus in a normal human brain? He should not like to be either the excisor or the excisee.

Marie asserts that in every aphasic there is trouble to comprehend spoken language, but that the tests ordinarily used are not adapted to bring this defect out. Dr. Lloyd thinks this is a criticism that should be taken to heart and put to the test by some of the advocates of pure motor aphasia. It will doubtless be found in many cases if the demands made of the patients are a little complicated (not merely an order to "put out your tongue," or "hold up your hand") that Marie is right in this respect. He knew that he had often found it to be so.

Another most important point is Maric's statement that in every case there is some loss of intelligence. It is surprising how commonly it is assumed that intelligence is intact in aphasia; that there is nothing the matter with the mind but a speech defect; although it should be evident that because of this very speech defect the difficulty of determining the integrity of the mental processes is almost unsurmountable. Dr. Lloyd would not tarry here to attempt to discuss the vast question of the dependence of thought upon the faculty of language; it is enough to poine out that this dependence is very close, and that those persons who calmly assume that in aphasia there is no mental defect, take much more for granted than either the facts or the science warrants. Upon this important subject Marie's criticism ought to do some good, and should invite to less superficial view of these cases. If the attempt is made to induce an ephasic to use his mind for abstract thinking, it is usually soon evident that he is out of his depth. He can "put out his tongue," and "hold up bis left hand," but he cannot sustain any complex train of thought, and the mere attempt soon worries and exhausts him. This raises the important medico-legal question of the will-making power of aphasics, ao in the celebrated Parrish case.

The emotional life is usually well preserved in aphasics, as Marie sayn, 
and this gives a superficial appearance of preserved intelligence. But the emotions are easily excited, even in the weak-minded, and are a very poor gauge of the extent of the intelligence.

Marie asserts that Broca's motor aphasia and Wernicke's sensory aphasia are very analogous, with the capital exception that in Broca's aphasia the patient cannot talk. This inability to talk is merely an anarthria, which is a sort of pseudo-bulbar palsy due to a lesion of the internal capsule. His scheme is a very simple one. The seat of all true aphasia is in a comparatively limited area of the brain cortex, and includes the supramarginal convolution, the angular gyrus, and the posterior ends of the two upper temporal gyres. When the capsule is involved, there is added an anarthria. Broca's classic convolution is thrown out entirely, as having nothing to do with aphasia. As has been already said, Dr. Lloyd thinks this cheme of Maric's is entirely too theoretical and dogmatic, and is open to the same criticism that can be brought against that of other schemers. But in some dctails, to which Dr. Lloyd had already referred, he bclieved Marie's criticism is bascd on just grounds, especially his claim that the superfine analysis of aphasia into many varietics is largely academic. Yet he would not go quitc so far as Marie. In a large and general way he belicved aphasia can be subdivided in to a few types. In one type the motor defcets predominate, and this can be called the motor type. In another, the scnsory element is more conspicuous, and this can be called the sensory type. But he believed it is a mistake to go much beyond this simple plan in our present knowledgc of aphasia. As for the localization of these defcets in the brain cortcx, he bclieved that the zone of speech is much more extcnded than the aren which Maric has mapped out.

Dr. F. X. Dercum briefly statcd Marie's position with regard to aphasia; namely, that aphasia is an intellcctual deficit; that it is a unit; that it is not made up of sensory aphasia on the one hand and motor aphasia on the other, but that by lesion of the zone of Wernicke there is established an intellectual deficit for the comprehension of spoken language; that in so-called sensory aphasia the lesion involves the zone of Wernicke, that in so-called motor aphasia thcrc is, in addition, an involvement of the region of the lenticular zone. Lesion of the lenticular zone gives rise to anarthria. Therefore in so-called motor aphasia, we have mercly ordinary Wernicke aphasia plus anarthria. Dr. Dcrcum then detailed the rcsults of his studies of fourteen cases of aphasia according to the method of Marie, for the determination of the presence of intellectual deficit. Some aphasics cannot comprehend a single word. More frequently they comprchend things that are relatively simple. As a rule they can execute simple instructions, but not complicated ones. Some aphasics have great trouble in executing a single act; others are embarrassed by a direction to perform two consecutive acts, and others fail when three or four are attcmpted. In all of his fourteen aphasics, Dr. Dercum found an unquestionable deficit. Four were unable to carry out any instructions, no matter how simple; two invariably failed when an instruction containing two factors was given; one was able to perform one instruction fairly well, but usually failed when the instruction contained two factors. Four were able to execute instructions containing two factors, but always failed when they contained three. Three could execute instructions containing three factors, but usually failed when this number was exceeded.

Similar facts were elicited when the attempt was made to have the 
patient carry out written instructions. Seven of the fourteen could read; that is, they could read single words, written or printed. Thus one patient could read the word "hand" and would correctly indicate the object upon his own person by raising' and exhibiting his own hand. He could read the word "head" and indicated this portion of the body. A short sentence embodying these two objects; namely, "hand" and "hcad," was now placed in writing before him, thus, "Put your hand on your head." He failed absolutely to comply. He evidently could not comprehend the sentence and was as helpless in the presence of a written instruction as he had been in the presence of the verbal instruction. Other interesting illustrations were given.

Dr. Dercum contended that the intellectual deficit maintained by Marie must be unhesitatingly admitted. He pointed out that this deficit is special in character. It differs, of course, from the deficit seen in arrested development on the one hand and in dementia on the other. The deficit is lacunar, involving one function or a closely rclated group of functions.

Dr. Dercum was unable to classify his aphasics into motor and sensory. He failed also when he attempted to arrange them into groups according to the presence or absence of anarthria. The motor speech difficulty appeared in each case as something added to the essential symptoms of the aphasia; an anarthria added to the failure to comprehend words or sentences.

Dr. Dercum's clinical studies were confirmatory of the results obtained by Marie. Further, Marie's contention that motor phenomena may be produced by involvement of the longitudinal bundle and by the isthmus which connects the zone of Wernicke with the region of the basal ganglia, bears a strong probability of truth, but it is only the confirmation of pathological observations which will definitely determine the question.

Regarding the third left frontal convolution, the occurrence of isolated lesions of this region in right-handed persons without producing aphasia must be extremely significant. Certainly such instances entitle us to the legitimate doubt as to the real function of the third left frontal.

Dr. E. D. Fisher said that what we understood by an intellectual defect must be in regard to spcech or in regard to writing. He had a patient who illustrates this. He attends to his business regularly. $\mathrm{He}$ is a hemiplegic and not an aphasic. He could not calculate in figures and yet his mind as a mind was as active as it ever was in business relations. He thinks there are many aphasics who are not intellectually aphasic in any way.

Dr. Starr said he had read these papers by Marie very carfully and given them a great deal of thought. As a lecturer on aphasia it was very interesting to draw diagrams, as Dr. Dercum said, and show what we thought ought to be the beautiful varieties of this disease, but, unfortunately, if you had to show the patients whom you thought illustrated the lecture it was sometimes hard to bring harmony between theory and fact. It had often been very difficult to find a case which corresponded exactly to the distinctions which were laid down in regard to motor and sensory aphasia. He believed Marie was right in calling attention to the fact that the majority of aphasics are doubly aphasic, that there was a sensory and a motor element combined in the majority of aphasics. He thought, on the other hand, that Marie had taken a decided step backward in trying to enforce this idea as applicable to every aphasic. He thought everyone who had studied 
a large number of aphasics could put his finger here and there on a case which was decidedly and distinctly motor, or entirely sensory, and if cases of this kind existed, it overthrew Marie's contention absolutely and brought us back to Dejerine's point. It seemed they were both right in part; that as Marie said aphasics were often both motor and sensory, but that Dejerine was also right in that there are cases of very limited lesion with purely motor or purely sensory symptoms. He had seen examples of both kinds. Exner was the first to figure it out in his wonderful diagrams 'way back in 1881, limited lesions causing pure types of aphasia, in Wernicke's region sensory aphasia and in Broca's motor aphasia. We have been acting upon this localization in brain surgery in the removal of tumors and abscesses from the different speech areas of the brain with success, and he therefore was not prepared to give up the idea of separate aphasic areas.

Dr. Joseph Fraenkel said that there are undoubtedly cases of pure sensory and pure motor aphasia occurring. It is true, of course, that such pure types are rare. Some years ago Dr. Onuf and he analyzed the elinical and autopsy findings of all cases of motor aphasia thoroughly reported in the literature. Out of a total of about Iro cases they found only about nine cases in which the speech disturbance was the resuit of 2 strictly localized lesion in Broca's center. Out of this number, only three showed the aphasic disturbances to be permanent. In the other cases there was a more or less marked recovery of the speech faculty in spite of the permanence of the lesion: Most of the other cases showed widely distributd lesions, so that it is impossible to conceive that these lesion should give rise to a clearly defined clinical picture. 